INTERNATIONAL JOURNAL OF SCIENTIFIC RESEARCH

\title{
LAPAROSCOPIC MANAGEMENT OF TYPE III PARAOESOPHAGEAL HERNIA WITH ORGANOAXIAL GASTRIC VOLVULUS : A CASE REPORT
}

\section{Surgery}

Dr Akash Gupta

Sandeep Dave*

Post doctorate fellow Minimal Access Sugery Care Hospital Raipur

Professor and Head Dept. of Minimal Access Sugery Care Hospital Raipur *Corresponding Author

Siddharth

Tamaskar

Consultant Dept.of Minimal Access Sugery Care Hospital Raipur

\begin{tabular}{ll}
\hline Ajit Mishra & Consultant Dept. of GI \& Minimal Access Sugery Care Hospital Raipur \\
\hline Vikram Sharma & Consultant Dept. of Minimal Access Sugery Care Hospital Raipur \\
\hline
\end{tabular}

\section{ABSTRACT}

Paraesophageal hernias are the results of defects in the diaphragmatic hiatus. Types II to IV hiatal hernias are also known as paraesophageal hernia. These hernias can be associated with life threatening complications such as gastric volvulus leading to necrosis or perforation of the stomach. Due to these potential complications it was thought that all paraesophageal hernia should be repaired upon diagnosis. Recent evidence, however demonstrated that a non surgical approach is a safe option in many cases. Surgical intervention is usually reserved for patients who are exhibiting symptoms secondary to paraesophageal hernia. We report an interesting case of a $72 y$ rs old female who presented at with Type III paraesophageal hernia with organo axial gastric volulus for which successful Laparoscopic reduction of volvulus with Diaphragmatic hernia repair with Nissen's fundoplication was done.

\section{KEYWORDS}

Paraesophageal hernia, Gastric volvulus, Nissen's fundoplication, GERD.

\section{INTRODUCTION:}

Hiatus hernia refers to herniation of elements of the abdominal cavity through the esophageal hiatus of the diaphragm and into the mediastinum. They are relatively rare, representing only about $5 \%-7 \%$ of all hernias, and can be associated with severe complications. Hiatal hernias have been associated with gastroesophageal reflux disease (GERD), and the prevalence and size of the hiatal hernia has been described to correlate with the severity of reflux. ${ }^{1}$ The presence of a hiatal hernia has also been identified in nearly $40 \%$ of obese patients. ${ }^{2}$ Some of the causes of hiatal hernias have been attributed to age, stress, and degenerative processes on the diaphragm. ${ }^{3}$ Most cases of hiatal hernia are acquired rather than congenital, although familial clustering has been reported. ${ }^{4}$

\section{CLASSIFICATICATION:}

Four types of hiatal hernias have traditionally been described. Type I hiatal hernia is a migration of the gastroesophageal (GE) junction into the posterior mediastinum, which is usually the result of deterioration of the phrenoesophageal ligament. ${ }^{5}$ Different types of collagen, particularly types I and III, have been found to be reduced in the phrenoesophageal ligament of patients with GERD and hiatal hernia. ${ }^{6}$ Type II is also referred to as a "true" paraesophageal hernia. Congenital defects in the esophageal hiatus can lead to paraesophageal hernias. ${ }^{7}$ Type III hiatal hernias are a combination of types I and II, in which both the GE junction and a portion of the stomach - usually the gastric fundus - herniate into the mediastinum. Type IV hiatal hernias contain stomach and other abdominal organs such as small bowel, colon, pancreas, or spleen in the mediastinum. The term giant paraesophageal hernia refers to large hiatal hernias where at least $50 \%$ of the stomach is in the mediastinum or the hernia measures at least $6 \mathrm{~cm}$ on endoscopy. ${ }^{8}$

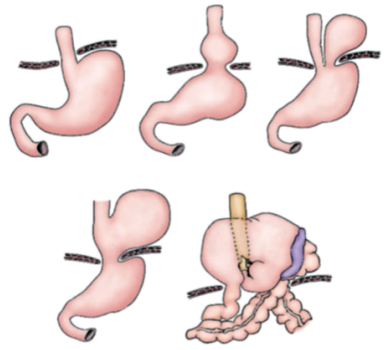

FIGURE 1 :Types of hiatus hernia. (A) Normal anatomy. (B) TypeI, or

sliding, hiatal hernia. (C) Type II or "true" paraesophagealhernia. (D)
Type III or "mixed" paraesophageal hernia. (E) Type IV paraesophageal hernia, containing other intraabdominal organs

Sources: Shackelford textbook of surgery $8^{\text {th }}$ ed

\section{CASE REPORT}

$72 / \mathrm{F}$, hypertensive was referred to our hospital with $\mathrm{H} / \mathrm{O}$ of intermittent abdominal pain associated with nausea and vomitting and decreased apetite. H/o of malena since 1day. She had no prior abdominal surgeries. Her Upper GI series was s/o - grossly dilated esophagus, stomach and duodenum. Her CT scan was s/o Paraesophageal hiatus hernia with oraganoaxial gastric volvulus. Given her symptoms and image findings a Laparascopic Paraesophageal hernia repair was offered to her.

\section{INVESTIGATION:}

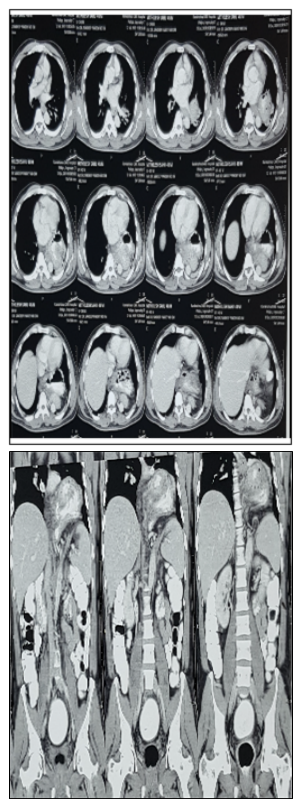

Figure 2 : CT image of patient showing type 3 paraesophageal hernia with gastric volvulus. 
OPERATIVE STEPS:

PATIENT POSITIONING:

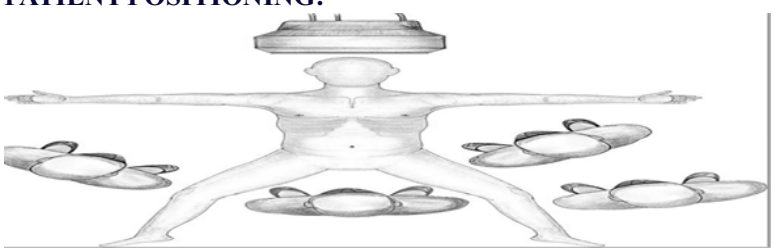

FIGURE 3 : Patient was positioned in a steep reverse tredlenburg position with the surgeon standing in between the two legs of the patient. The camera person is on the right side while the assistant surgeon is on the left side of the patient. Monitor is placed on the head end.

Sources: Shackelford textbook of surgery $8^{\text {th }}$ ed

\section{PORT PLACEMENT:}

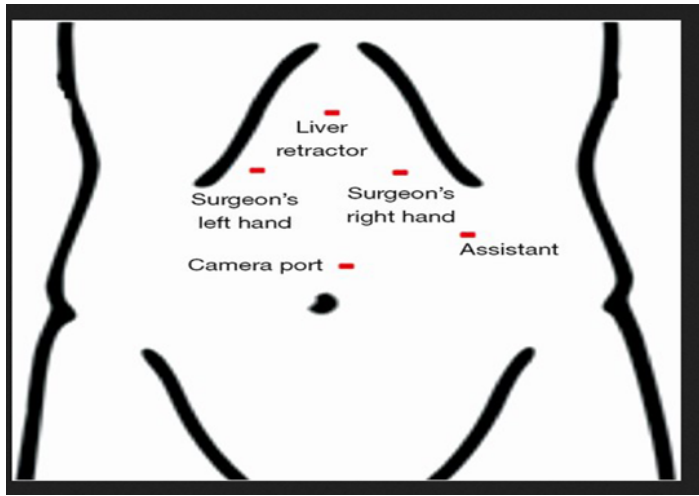

FIGURE 4: Sketch diagram depicting various port placement.

Sources : www.googleimages.com/port placement

\section{LIVER RETRACTION:}

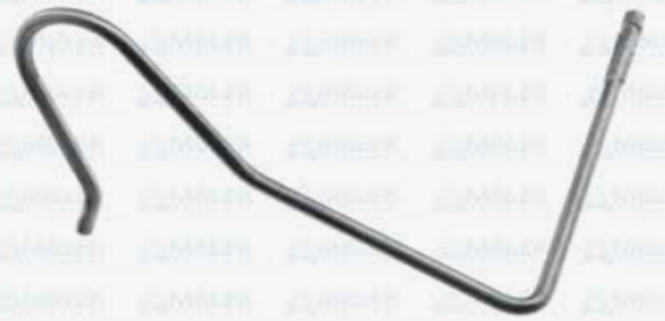

FIGURE 5 : The liver was retracted by an instrument known as "Nathanson" liver retractor introduced through the epigastric port.

Sources: www.googleimages.com/nathanson retractor

\section{OPERATIVE STEPS:-}

The key operative steps in our procedure included :-

- Reducing the gastric volvulus

- Excision of the hernia sac

- Preservation of both vagal nerves

- Complete mobilisation of gastric fundus by dividing short gastric vessels

- Extensive mediastinal dissection to obtain $3 \mathrm{~cm}$ length of tension free intra-abdominal esophagus

- Creation of a large retroesophageal space.

- Cruroplasty using 2-0 ethibond suture along with a composite mesh

- Creation of a $2.5 \mathrm{~cm}$ "floppy" fundoplication.

\section{POSTOPERATIVE COURSE :}

The patient was successfully extubated and shifted to recovery room. The patient did well in the postoperative period. Liquids were started $6 \mathrm{hrs}$ after the surgery. Soft diet was initiated $48 \mathrm{hrs}$ after the surgery. Drain was removed on $2^{\text {nd }}$ postoperative day. Suture removal done on $8^{\text {th }}$ postoperative day. There were no postoperative complication.

OPERATIVE IMAGES:

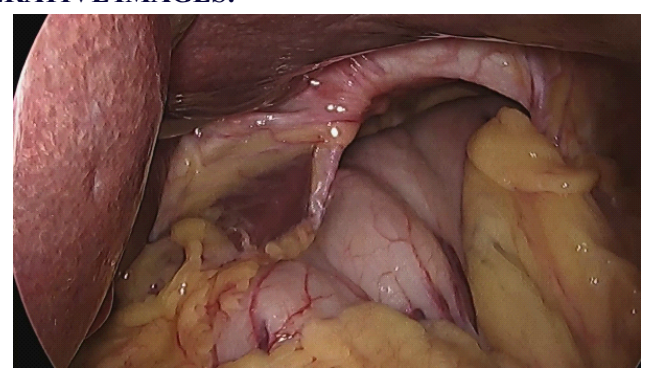

Figure 6 : Initial laparoscopic view showing a wide hiatus hernia with organoaxial gastric volvulus

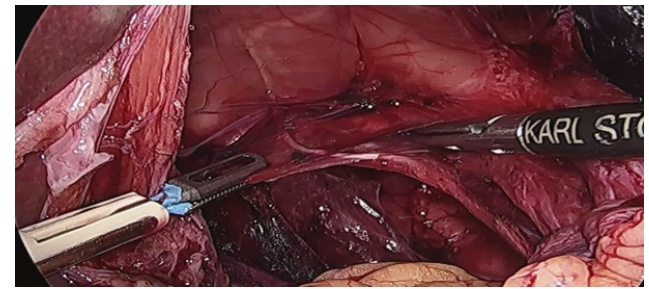

Figure 7 : Preservation of posterior division of vagus nerve

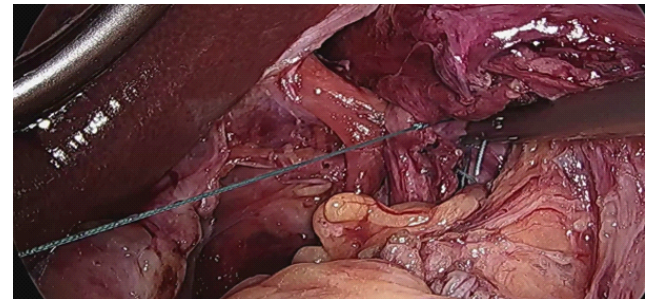

Figure 8: Cruroplasty performed with 2-0 ethibond suture

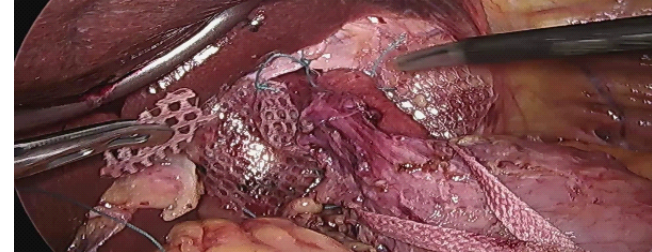

Figure 9: Hiatus reinforcement with a composite mesh

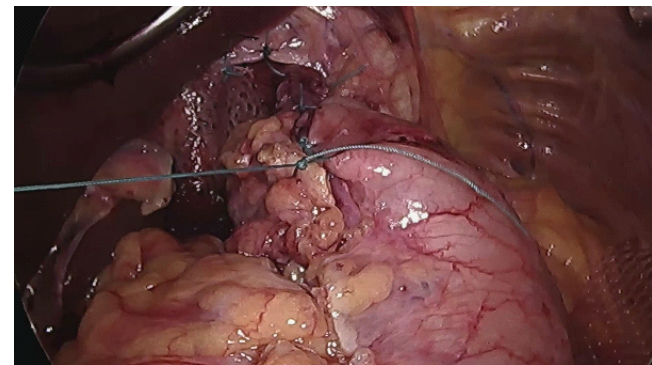

Figure 10: Completion of Nissens $360^{\circ}$ fundoplication

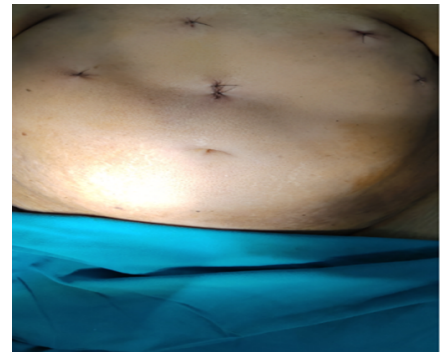

Figure 11 : Postoperative image of the patient showing port placement

\section{CONCLUSION}

Laparoscopic repair of paraesophageal hiatal hernia has become the 
standard of care in many centers across the world. When performed in esophageal centers of excellence, by an experienced esophageal surgeon, the short-term outcomes of laparoscopic repair compare favorably with the outcomes of open repair. ${ }^{9,10}$. However, not every surgeon is necessarily experienced enough to do these complex operations independently. There are several key elements to laparoscopic repair of PEH: (1) complete reduction of the hernia sac and contents; (2) careful preservation of the anterior and posterior vagus nerves; (3) mobilization of the gastroesophageal fat pad and identification of the GEJ; (4) recognition and management of a shortened esophagus (extensive mediastinal mobilization and performance of a Collis gastroplasty when necessary); (5) preservation of crural integrity and closure of the hiatal defect without tension with liberal use of an induced pneumothorax to yield a "floppy" diaphragm during repair; selective use of mesh reinforcement only if other measures fail; and (6) performance of an antireflux procedure or perhaps in select patients a gastropexy. Laparoscopic repair of PEH can provide excellent patient satisfaction and symptom resolution when performed by surgeons with extensive experience in minimally invasive and open esophageal surgery.

REFERENCES:

Maish MS, DeMeester SR. Paraesophageal hernia. In: Cameron JL, ed. Current Surgical Therapy. 8th ed. Philadelphia: Mosby; 2004:38.

2. Che F, Nguyen B, Cohen A, Nguyen NT. Prevalence of hiatal hernia in the morbidly obese. Surg Obes Relat Dis. 2013;9(6):920-924

3. Kissane NC, Rattner DW. Paraesophageal and other complex diaphragmatic hernias. In: Yeo CJ, ed. Shackelford's Surgery of the Alimentary Tract. 7th ed. Philadelphia: Saunders; 2012:494.

4. Baglaj SM, Noblett HR. Paraesophageal hernia in children: familial occurrence and review of the literature. Ped Surg Int. 1999;15:85-87.

5. Hashemi M, Sillin LF, Peters JH. Current concepts in the management of paraesophageal hiatal hernia. J Clin Gastroenterol. 1999;29:8-13.

6. Von Diemen V, Trindade EN, Trindade MR. Hiatal hernia and gastroesophageal reflux: study of collagen in the phrenoesophageal ligament. Surg Endosc. 2016;30(11):5091study of collagen in the phrenoesophageal ligament. Surg Endosc. 2016;30(11):5091-

7. Kleitsch WP. Embryology of congenital diaphragmatic hernia. I. Esophageal hiatus hernia. Arch Surg. 1958;76:868

8. Melvin WS, Perry KA. Paraesophageal hernia-open repair. In: Fischer JE, ed. Fischer's Mastery of Surgery. 6th ed. Philadelphia: Lippincott Williams \& Wilkins; 2012:760.

9. Nason KS, Luketich JD, Qureshi I, et al. Laparoscopic repair of giant paraesophageal hernia results in long-term patient satisfaction and a durable repair. J Gastrointest Surg. 2008:12(12):2066-2075, discussion 2075-2077.

10. Skinner DB, Belsey RH. Surgical management of esophageal reflux and hiatus hernia: long-term results with 1,030 patients. J Thorac Cardiovasc Surg. 1967;53:33-54. 